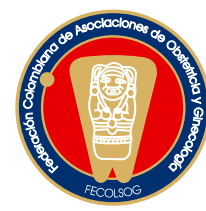

\title{
EDITORIAL
}

\section{¿QUÉ TAN CERCA ESTAMOS DEL CONTROL DEL CÁNCER CERVICAL Y LA INFECCIÓN POR EL VIRUS DE PAPILOMA HUMANO?}

\section{How close are we to controlling cervical cancer and human papillomavirus?}

Gonzalo E. Pérez, M.D.

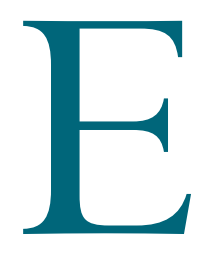
n los últimos 30 años hemos sido testigos del vertiginoso crecimiento de la información y del conocimiento relacionados con la infección por el virus de papiloma humano (VPH).

La razón de ello es la hoy clara asociación causal que existe entre ésta condición y múltiples tumores malignos, algunos de los cuales como el cáncer de cuello uterino, son problemas de salud pública, que han urgido la necesidad de encontrar soluciones.

Y es que desde finales de la década de los 70 muchos grupos de investigación se dieron a la tarea incesante de estudiar el fenómeno de la infección, de la transmisión y los procesos de trasformación vinculados, desde diversos enfoques que incluyen las ciencias básicas, la epidemiología molecular y la epidemiología clínica. A finales de dicha década se identificó el genoma viral en tejido proveniente de muestras de carcinomas cervicales, la clonación del virus y su vinculación con una gran familia de virus epiteliotrópicos y la interpretación de los mecanismos de trasformación. Todo ello se complementó en la década de los 80 con los resultados de los primeros estudios de casos y controles que mostraron una fuerza de asociación que no dejaba ninguna duda acerca de la relación entre VPH y el cáncer de cuello uterino y se clasificó como un virus con capacidad oncogénica. ${ }^{1-3}$ En la década de los 90, los estudios de cohorte confirmaron los resultados y dieron aún más peso a la evidencia. Uno de ellos fue conducido en el Instituto Nacional de Cancerología en Bogotá y

* Ginecólogo Oncólogo, correo electrónico: gperez@interred.net.co es uno de los estudios de referencia a nivel mundial. ${ }^{4}$ Este nuevo siglo se inaugura con el desarrollo de las vacunas preventivas, ${ }^{8}$ que no solo constituyen la prueba inequívoca de la asociación causal, sino que nos llenan de esperanza hacia el futuro.

Pero el camino por recorrer antes de que logremos una reducción de las tasas de incidencia de la infección y sus consecuencias y acaso la erradicación de las mismas, es aún muy largo. Por ahora tenemos que aceptar, que la carga de las enfermedades relacionadas con el VPH es muy importante. El riesgo de contraer la infección a lo largo de la vida para cualquier persona sexualmente activa es del $50 \%{ }^{5}$ cada año unos 300 millones de personas adquieren la infección, 30 millones de personas sufren de verrugas genitales, 30 millones más desarrollan lesiones intraepiteliales de bajo grado, 10 millones presentan lesiones de alto grado o precancerosas y alrededor de medio millón, se diagnostican con cáncer invasivo, cuya mortalidad oscila de acuerdo con la región, pero en promedio tiene valores que oscilan entre un $40 \%$ y un $50 \%$ en los estados avanzados. ${ }^{6}$

El 80\% de los casos de cáncer invasivo se diagnostican en países pobres, ubicados en el hemisferio sur y especialmente en los continentes africano, americano y asiático. Es consecuencia de la pobreza, falta de oportunidad de la atención médica, amén de otros múltiples factores.

La implementación de programas preventivos mediante pruebas de cribado con citología ha demostrado ser efectiva para lograr la reducción de las tasas de incidencia de la enfermedad, como se demostró en los Estados Unidos y en Inglaterra a 
fines de la década de los 80 , cuando la práctica activa del cribado citológico rompió la inercia existente en los indicadores de cáncer de cuello uterino y redujo dramáticamente las tasas de incidencia; ${ }^{7}$ pero desafortunadamente, dichos programas son inexistentes o inoperantes en los sitios de mayor incidencia, donde el problema persiste con mínimas modificaciones.

Entre tanto en los países desarrollados, los avances tecnológicos ofrecen otras alternativas para el diagnóstico, tales como las técnicas de citología líquida y las pruebas de detección y tipificación del ADN viral que buscan optimizar los programas de prevención secundaria bajo un concepto de costo efectividad.

No es el objetivo de éste editorial el profundizar en cada uno de los puntos citados, sino el de ofrecer un panorama de la situación y plantear para finalizar un par de inquietudes que considero pertinentes.

En la era de la citología líquida, de las pruebas de detección y tipificación del ADN y de la vacuna preventiva, debemos hacer esfuerzos para lograr que todos estos avances traigan beneficio a nuestros pacientes; para ello tendremos que definir la mejor aplicación de todas estas herramientas en cada uno de los escenarios. Los objetivos y las prioridades serán seguramente diferentes en los países desarrollados y en los países en vía de desarrollo. En los primeros, además de buscar la reducción de las ya bajas tasas de incidencia se pretenderá reducir los costos operativos y optimizar los procesos. En los segundos, el objetivo primordial será la reducción de las elevadas tasas de incidencia. La prioridad por otra parte en nuestros países deberá ser la organización de programas de cribado eficientes. La vacunación debe entenderse como una inversión en el tiempo para cualquiera de las dos situaciones, pero especialmente para la de los países pobres, dado que los resultados de la misma en términos de reducción de las tasas no serán posiblemente evidentes antes de algunos años. Además debe entenderse que las vacunas podrán prevenir las enfermedades asociadas con los tipos virales incluidos en ellas y que la mayor efectividad se verá en la población previamente no expuesta al agente. ${ }^{8,9}$

Se requiere entonces compromiso, organización y una visión a futuro. Nuestros gobiernos deben entender que es necesario invertir en salud y educación. La mayor riqueza de una nación es su capital humano.

\section{REFERENCIAS}

1. Schiffman MH, Bauer HM, Hoover RN, Gloss AG, Cadell DM, Rush BB, et al. Epidemiologic evidence showing that human papillomavirus infection causes most cervical intraepithelial neoplasia. J Natl Cancer Inst 1993;85:958-64.

2. Munoz N, Bosch FX, de Sanjose S, Herrero R, Castellsague $\mathrm{X}$, Shah KV, et al. Epidemiologic classification of human papillomavirus types associated with cervical cancer. $\mathrm{N}$ Engl J Med 2003;348:518-27.

3. Bosch FX, de Sanjose S. Chapter 1: Human papillomavirus and cervical cancer-burden and assessment of causality. J Natl Cancer Inst Monogr 2003;(31):3-13.

4. Munoz N, Mendez F, Posso H, Molano M, van den Brule AJ, Ronderos M, et al. Incidence, duration, and determinants of cervical human papillomavirus infection in a cohort of Colombian women with normal cytological results. J Infect Dis 2004;190:2077-87.

5. Centers for Disease Control and Prevention. Genital HPV infection Fact Sheet. Rockville, Md: CDC National Prevention Information Network; 2004. [visitado en 2004, Sept. 21] Disponible en: http:// www.cdc.gov/std/HPV/hpv.pdf.

6. Ferlay J, Bray F, Pisani P, Parkin DM. GLOBOCAN 2002: Cancer incidence, mortality and prevalence worldwide, version 2.0. IARC Cancer Base No. 5. Lyon, France: IARC Press; 2004.

7. Quinn M, Babb P, Jones J, Allen E. Effect of screening on incidence of and mortality from cancer of cervix in England: evaluation based on routinely collected statistics. BMJ 1999;318:904-8.

8. Koutsky LA, Ault KA, Wheeler CM, Brown DR, Barr E, Alvarez FB, et al. A controlled trial of a human papillomavirus type 16 vaccine. $\mathrm{N}$ Engl J Med 2002;347:1645-51.

9. Villa LL, Costa RL, Petta CA, Andrade RP, Ault KA, Giuliano AR, et al. Prophylactic quadrivalent human papillomavirus (types 6, 11, 16, and 18) L1 virus-like particle vaccine in young women: a randomised doubleblind placebo-controlled multicentre phase II efficacy trial. Lancet Oncol 2005;6:271-8. 